\title{
Cooperation in the Prisoner's Dilemma: The Rules Importance to Achieve Cooperation Equilibrium
}

\author{
Rodolfo Coelho Prates \\ Universidade Positivo, Curitiba, Brazil
}

\begin{abstract}
This paper discusses the role of cooperation in the static game involving the prisoner's dilemma. As depicted in the literature, the cooperation in games like that only happens when there is repetition of the decision situation. Initially, the paper presents a panoramic development of game theory and discusses the prisoner's dilemma, as well as its use to illustrate Nash's concept of equilibrium. Then, the paper discusses some concerns of the New Institutional Economics and how rules can influence the cooperation between agents. The implementation theory is used in order to establish the relationship between two major areas of study—Game Theory and the New Institutional Economics. That theory, which is a branch from the game theory, assumes the presence of a planner, who previously plans the final equilibrium of the game, and determines the rules of the game to achieve the expected balance. Based on that, the paper first discusses the rules of the prisoners' dilemma and then presents a new game in which the original rules were changed so that cooperation is achievable. The new prisoners' dilemma game allows for two different situations in which Nash Equilibrium can be reached the non-cooperative situation (traditional one) and a new cooperative equilibrium, showing that the rules influence cooperation. The theoretical results strengthen the legitimacy and the role of institutions-rules, laws and other instruments—as positive guidelines, informing social, economic, and business action.
\end{abstract}

Keywords: game theory, prisoner’s dilemma, new institutional economics, cooperation

\section{Introduction}

There has been a remarkable expansion of the game theory and it has penetrated many different fields of knowledge. Since it first arose in the mid-1940s, it has been consolidated as one of the most important fields of study, not only of mathematics but also of economics, psychology, and biology, to name a few, and it has now become a major force in the scientific field.

The basis of the game theory is interaction between individuals. Within its extreme rationality, its goal is to determine, whenever possible, a balance resulting from interactions. This balance may be good or bad or lie somewhere in between the two extremes. Nevertheless, it does not fall to the game theory to decide which balance is preferable as it is devoid of values (Dixit \& Nalebuff, 1993).

The great capacity of the game theory is that it can simulate and analyze social situations normatively, in that it allows interactions to be analyzed. Its flexibility makes it possible to understand situations in a wide variety of scientific fields and also in a wide variety of analytical structures in terms of individuals,

Rodolfo Coelho Prates, Ph.D., Associate Professor, Graduate Business School, Universidade Positivo.

Correspondence concerning this article should be addressed to Rodolfo Coelho Prates, Av. Pedro Viriato Parigot de Souza, 5300 Curitiba, Brazil.E-mail: rodprates@hotmail.com. 
organizations, and nations. Furthermore, since the development of the implementation theory, it has also helped to understand precisely the role of institutions when setting and regulating games. This resource has become very useful, especially when it comes to analyzing environments that are governed by institutions, whose role is to set the rules for living together, be they social, such as political and legal rules, or in business and economics, such as the roles of regulatory agencies and agencies that defend competition.

Equally important is the light that new institutional economics has cast on the old concepts of the neoclassical theory of the firm. It has built a bridge between purely technical decisions related to production parameters and large social structures (Klein, 1999). The transaction cost theory and the whole discussion concerning property rights constitute the bases for a broader understanding of economic relationship. Nevertheless, the most important contribution of new institutional economics is recognizing the importance of institutions regarding economic behavior (Furubotn \& Richter, 2005). Mature institutions set clear rules of play, culminating in improved conditions for the development of both companies and societies.

Both the game theory and new institutional economics assume that cooperation is a socially desirable situation, but it does not arise spontaneously or automatically because opportunistic actions, based on self interest, generate worse results than those achieved when cooperation is possible (Williamson, 1985). This implies that one of the functions of institutions is to propose rules that value cooperation. Cooperation is understood to be a balance whose results provide the greatest possible level of satisfaction for all players.

Given the considerations outlined above, the aim of this study is to discuss the possibility of cooperating in the game and the prisoner's dilemma through changing the rules, focusing on the relationship between new institutional economics and the game theory. As is well known, the prisoner's dilemma is a kind of allegory to demonstrate Nash's concept of equilibrium. And it was chosen as an operational strategy due to its widespread penetration and its conceptual ease because, as Axelrod (1997, p. ii) has pointed out, "the two-person iterated prisoner's dilemma is the Escherichia coli of the social sciences".

In addition to this introduction, a panorama of the game theory is presented in Part 2, highlighting the prisoner's dilemma and some points concerning cooperation. In Part 3, there is a panoramic view of some elements of new institutional economics. In Part 4, the convergence between the game theory and new institutional economics is shown, a link provided precisely by the implementation theory. The implementation of a new game is conducted in Part 5, where, through the changing of the rules, there is a glimpse of the possibility of cooperation. Part 6 has an analysis of how employers' organizations and trade unions can benefit from the implementation structure. This analysis could be extended to such topics as the relationship between suppliers and buyers, the formation of joint ventures and outsourcing. Finally, Part 7 has the final considerations of this article.

\section{Game Theory}

Although the name looks playful, the game theory, from the very beginning, has been a hard nut to crack. This is because it is a branch of mathematics, although other fields have incorporated its concepts and made very expressive contributions to it. Even though, it is possible to track down previous works, such as the Cournot equilibrium for homogenous oligopolies, there is a consensus that it owes its formalization as a scientific field to the publication of "Game Theory and Economic Behavior" in 1944, by John Von Neumann and Oskar Morgenstern. In this work, in addition to the bases of other fields related to economics, such as uncertainty, they constructed the entire framework of the game theory (Von Neumann \& Morgenstern, 1944). 
It is also true that Von Neumann himself had already explored the game theory by proving the solution to the minimax in 1928 and by publishing an article entitled “Theory of Games I, General Foundations” in 1940, the aim of which was to show that economic behavior in certain circumstances was the same as strategy games (Poundstone, 1992). But it was the 1944 publication that made this new branch stand out and aroused the attention of so many other researchers, both in the field of mathematics and economics, to this new scientific field.

In concept, the game theory can be understood as the strategic interactions between rational agents. Looking at it more broadly, it is the mathematical vision of the workings of social behavior. This is due to the pragmatic nature of Von Neumann himself. Unlike many other mathematical theoreticians, such as Gauss, Riemann, Hilbert, and Poincarré, Von Neumann, besides being a deep thinking theoretician, was always more interested in applications that could be constructed using mathematics. His works cover a wide range of themes, where the only common denominator is pragmatism, such as computing and quantum mechanics. In this aspect, the game theory is the application of mathematics to the social field (Poundstone, 1992).

Whether theoretical or applied, mathematics is the exercise of logic and requires rationality. All of its contributions and ramifications are also expected to have their original characteristics. Therefore, it is a spontaneous derivation that rationality in the structure of game theory is a neuralgic point. It is something natural, like finding chlorophyll in the cellular structure of plant leaves. As North (1993, p. 27) stated, "the power of the game theory is to turn the structure into a formal argument in accurate terms”.

The game theory, since its origin, has branched out into other fields such as economics, law, philosophy, the armed forces, journalism, biology and politics. But no matter how it is applied, it develops autonomously, independent of its adherence to reality (Greif, 1997), although it has been labeled as an application.

After Von Neumann and Morgenstern, many researchers, especially mathematicians, became interested in the game theory. They created games of complete and incomplete information, extensive games, Bayesian games, repetitive games, sub-games, dynamic games, and corporate and non-corporate games (Osborne \& Rubinstein, 1994).

But none of these contributions made an impact like the equilibrium proposed by John Forbes Nash. The Nash equilibrium is one of the main pillars of the game theory and was developed during his doctoral thesis, which he defended in 1950 at Princeton University, under the supervision of the mathematician Tucker. Entitled Non-cooperative games, the thesis proposes a new equilibrium and a new vision of the functional structure of the games. Put simply, the Nash equilibrium occurs when a player does his best, given that his rivals also do their best (Osborne, 2004).

It is worth pointing out that not all games have the Nash equilibrium, but by the same token there may be several equilibriums in the same games. Furthermore, concerning his equilibrium, Nash states that when players act individually and rationally, they cannot maximize the social gain that would be achieved if they cooperated with one another (Osborne \& Rubinstein, 1994).

After the formulation of the Nash equilibrium, many examples were constructed for the purpose of explaining situations in which the equilibrium could be achieved. The best known and the most emblematic of these may be the prisoner's dilemma.

The prisoner's dilemma was originally formulated by the mathematicians Merrill Flood and Melvin Dresher in 1950 while they were working at the Research and Development Corporation (RAND), a non-profit institution dedicated to making strategic analyses for the American armed forces. Later, the Canadian 
mathematician and supervisor of Nash's thesis, Albert W. Tucker, reworked it into the form that we know today. Tucker used the dilemma as a teaching resource in his classes when dealing with the Nash equilibrium (Poundstone, 1992).

The prisoner's dilemma can be set out thus: two suspects of a crime are captured and placed in separate cells in such a way that communication between them is impossible. Interrogated at different times, each of them receives a proposal with two options: to confess or not confess to the crime. The terms of the proposal are that if they both confess, each will be punished with a five-year sentence. If both decide not to confess, they will remain in prison for another year until the investigation is concluded. If only one confesses, the one who confessed is immediately released and the other is imprisoned for ten long years (Osborne \& Rubinstein, 1994).

This game is strategically shown in Table 1 . It should be noted that the values therein are how long they will remain in prison. Therefore, it is preferable to remain behind bars for as short a period as possible.

Table 1

Strategic Representation of the Prisoner's Dilemma

\begin{tabular}{|c|c|c|c|}
\hline & & \multicolumn{2}{|c|}{ Prisoner A } \\
\hline & & Guilt confessed & Guilt not confessed \\
\hline \multirow{2}{*}{ Prisoner B } & Guilt confessed & 5.5 & 0.10 \\
\hline & Guilt not confessed & 10.0 & 1.1 \\
\hline
\end{tabular}

Note. Source: Adapted from Osborne and Rubinfeld (1994).

The best option for both suspects is to deny the crime, which is a gain for cooperating. However, they would be in a weak position because if the other confesses, the one who does not will receive the maximum sentence. With this in mind, no matter what the other prisoner does, the best strategy is to confess and thereby ensure a shorter sentence or no sentence at all. Therefore, both choose to confess. This is Nash's equilibrium. Once this equilibrium has been achieved, there is no incentive for the agents to change their mind. The recommended procedure for achieving Nash's equilibrium in more complex games is the best response, also known as a function of reaction.

As Axelrod $(1984,2001)$ pointed out, in games similar to the prisoner's dilemma if both players cooperate, they do well. Nevertheless, there is a natural temptation to defect. This is exactly the type of opportunistic temptation that results in non-cooperation, i.e., these conditions (rules) result in failure when attempting to achieve mutual benefit through cooperation.

As time went by, analyzing the prisoner's dilemma constituted a special ramification within the game theory, both in theoretical and empirical studies, to the point where Axelrod (1984) described it as the E. coli of the social sciences. The work of Dixit and Nalebuff (1993) contained a wide range of situations that can be described using the prisoner's dilemma. This becomes real because agents have simultaneously competitive and complementary interests.

The prisoner's dilemma is a central theme because it exposes a considerable duality: choice between cooperation and defection. Axelrod (1984) claimed that in ephemeral interactions, cooperation is difficult to achieve. The choice of cooperative strategies depends on three basic categories: making the future more important relative to the present; changing the pay-offs to the players of the four possible outcomes of a move; and teaching the players values, facts, and skills that will promote cooperation (Axelrod, 1984, p. 126).

In fact, the duration of the game is a very important condition for shifting to cooperation. 
If the strategic setting allowed long enough interactions between individuals, much of the advice pointed to reasons why an egoist should be willing to cooperate even though there is a short-term incentive not to cooperate. But if the interaction was not very durable, then an egoist would be better off going for short-run benefits, and defecting. (Axelrod, 1984, p. 124)

This result is confirmed by Andreoni and Miller (1993) and Normann and Wallace (2011), who showed that the cooperation could be achieved more easily when the game can contain more repetitions. Furthermore, knowledge of the rules for concluding the game was not shown to be an element that facilitates cooperation between the players (Normann \& Wallace, 2011).

In addition to the duration of the game, collaboration has to do with the nature of the players, the interdependence of strategies and other environmental circumstances. In the organizational environment, cooperation has to do with the

...competitive positioning pursued by companies; the impact of external factors resulting from competitive interactions; the nature of the flow of information, the chance of repetition of experiments; the presence of reliable interlocutors who are capable of initiating dialogue and negotiation between the parties; the possible synergies and gains resulting from cooperation, etc.. (Vale \& Lopes, 2010, p. 727)

\section{New Institutional Economics}

An a priori assumption of the game theory is the rationality of the agents in all types of games, and this extends to the whole of neoclassical microeconomics, the objective of which is to analyze how the price system affects the choice of agents, whether they are producers or consumers, and it was this questioning of the efficiency of pricing that led to a new understanding of economic relationships.

This questioning can be better understood using an allegory by Simon (1991). Simon imagines that if Martians were to aim a special telescope at the Earth which would afford them a view of its geographical forms and also observe production relationships, the Martians would observe green stains and red lines. The green stains are companies and the red lines are market transactions. When one has knowledge of the true meaning, one questions the denomination of the large green stains connected by the red lines as "market economy" rather than "organizational economy". This allegory illustrates clearly the view of the how the production economy was viewed, where relationships boiled down to a production function.

And two works deserve recognition for paving the new way of understanding economic relations, both penned by Ronald Coase. The first is his 1937 article "The Nature of the Firm”, in which he discusses the cost of using pricing, i.e., the cost of making transactions by way of market mechanisms. This cost became known as transaction costs.

In this new discussion, the concepts of marginality and substitution were not sufficiently wide-ranging to explain the different forms of organization in which firms found themselves. In this sense, Cárdenas and Ojeda (2002) claimed that the transaction cost theory did not arise in opposition to the neoclassical theory, but to complement its postulates.

Indeed, the transaction cost theory has a broader analytical level than the neoclassical theory of the firm. Williamson (1998) proposed four levels of social analysis. The broadest one is the social level, wherein lie the rules, customs, and traditions; the second level is the institutional environment, with the structures that define the rules of the game in which economic activities are organized; the third level is where the transaction costs occur in which the agents are guided by the rules of the game and are organized in different alternative 
production modes; and the fourth level is the company's decisions on production, where the analyses of the classical theory of the firm are concentrated.

It is at the third level that the analytical elements explain why there are so many types of organization to be found. The transaction cost theory describes the firm as a governance structure, i.e., it provides a response concerning the limits of the firm.

One of the central elements is the matter of contracts. In the view of Heckathorn and Steven (1987), contractual relations have a temporal dynamic. Just prior to negotiations, each agent is contractually involved because he perceives an opportunity for mutual gain. This is the time of joint rationality. During the recruitment stage, it is established that the agents should divide gains and costs. This is rational concession. And finally, there is the problem of defection. This is the phase of individual rationality.

Even taking this dynamic into account, contracts are necessarily incomplete due to limited rationality. This inclusion of this matter is undoubtedly due to the influence of the Carnegie-Mellon University tradition, the main exponent of which is Herbert Simon and his fruitful works on human cognition (Simon, 1955).

Although it may seem paradoxical, the transaction cost theory also strays into the neoclassical theory, and this is due to Hicks (1935), who analyzed currency demand. Hicks stated that there was friction in the economy resulting from the purchase and sale of assets. When returns are small, within the margin, individuals prefer, when acting rationally, to have a no return cash balance because the transaction cost will be too heavy a burden on the operation. Along the same lines, Demsetz (1964) understood that the transaction cost can be defined as the cost of exchanging title deeds. It is worth highlighting that in the neo-classical approach, costs that occur within companies are not transaction costs. Transaction costs are those that occur between companies or individual beginning with the market exchange (Lee \& Sabourian, 2007).

Coase's (1960) second work is "The Problem of Social Cost". In this work, when dealing with property rights, Coase voices his understanding of the importance of institutions regarding economic performance. Although this understanding was known in the neoclassical tradition, especially by Marshall, the consolidation of its mathematical formalism overshadowed interest in institutional phenomena (Furubotn \& Richter, 2005). North (1990) understood that institutions constitute the set of formal and informal rules that defined human relations. But in general, there is a consensus that institutions actually constitute the rules of the game (Heckathorn \& Steven, 1987; Williamson, 1998). Aoki (2001) complemented this by stating that institutions were a self-sustaining mechanism of shared beliefs concerning how a game was played.

Focusing specifically on the prisoner's dilemma, Allen (1999) claimed that it only exists because of transaction costs. And examples of analogies can be found in other fields that depend on the protection of property rights, such as the industrial organization, the labor market, and international trade. Furthermore, Williamson (2007), when commenting on the prisoner's dilemma, claims that the Transaction Cost Theory assumes that criminals, when they foresee their capture, can take action to prevent a confession. Thus, ex ante governance mechanisms can be constructed as a future precaution.

\section{Convergence}

In addition to the advances outlined above, one of the main fields of the game theory is the implementation theory. Developed by Leonid Hurwicz throughout the 1960s, this branch of the game theory, without abandoning all the requirements of formalization, shifted its attention to the markets and the economic system. Unlike other games, the implementation theory assumes the presence of a planner, who may be the 
head of the household, the director of an organization or the state. The head of the household sets the rules of behavior in the domestic environment, the company director sets down the norms in the productive environment and the state passes laws for living in a society.

It is worth pointing out that the planner chooses, within the implementation theory, the desired results of the game and the rules for interaction between the participants. This agent has mechanisms to force the other agents to play the game. Mechanisms can be coercive or punitive, but they do not have the power to force players to take actions that culminate in a certain result, as this is achieved through the interaction among the players themselves (Osborne \& Rubinstein, 1994). The planner should take into account that the behavior of the agents is influenced by the amount of information they possess and what the other agents expect from their interactions (Cárdenas \& Ojeda, 2002).

Therefore, the implementation theory is a dual (inverse) way of analyzing games. The traditional form is to find a solution or equilibrium for a given game, whereas in the implementation theory, the aim is to design a game with a determined balance in mind. Nowadays, the implementation theory is an important mechanism for achieving specific social and economic goals, providing the planner with the skill to implement games adequately (situations, laws, or institutions, for instance) so that the desired results are attained.

New Institutional Economics, summarized by North (1990), understands institutions as constituting formal rules that delimit social interactions. Therefore, the role of the state stands out because it falls to the state to establish the decisive elements for the rules of the game. According to North (1981, p. 24), "the basic services that the state provides are the underlying rules of the game", which, through norms, currently in the form of laws, specifies the fundamental rules of competition and cooperation, and also guarantees property rights in such a way that transaction costs are reduced and social production is thus maximized.

Therefore, one can see that the planner in the implementation theory plays the same role that institutions have within New Institutional Economics. Implementing a mechanism or game is constructing an institution that provides rules for social behavior. Other similarities can be seen, such as the asymmetry of information in the system and the existence of a planner. Furthermore, transaction costs manifest as requirements of information and ownership rights are related to the set of actions of each player (Cárdenas \& Ojeda, 2002).

\section{Implementation: Modified Prisoner's Dilemma}

In this part, a new implementation is presented in which the presence of transaction costs does not hinder the achievement of a cooperative equilibrium. The focus adopted here starts out with the assumption that transaction costs partially account for the prisoners' dilemma. Another cause of the dilemma has to do with the characteristics of the game's implementation, i.e., it is an institutional problem, since the rules of the game oblige one to choose only one equilibrium.

Here a new implementation is proposed, in which small changes to the structure of the game enable players not only to adopt individual action but also to cooperate with each other without any form of disloyal or opportunistic action. For this, it is necessary to clarify the principles used to modify the original structure of the prisoners' dilemma. The rules then become:

(1) A person cannot be held prisoner if he is innocent or if there is no evidence to convict him;

(2) A person will be imprisoned if he is guilty;

(3) If a person is guilty and helps to clear up the crime he will be given a reduced sentence.

Table 2 compares the rules of the prisoner's dilemma in its original and modified forms. One can see that 
there are no new rules, only the reformulation of its structure.

Table 2

Rules of the Original and Modified Prisoner's Dilemma

\begin{tabular}{lll}
\hline \multirow{2}{*}{ Characteristic of the prisoner } & \multicolumn{2}{c}{ Time behind bars } \\
\cline { 2 - 3 } & Original prisoner's dilemma & Modified prisoner's dilemma \\
\hline Innocent or no evidence to convict & Reduced sentence & Set free \\
Guilty & Maximum prison sentence & Maximum prison sentence \\
\hline
\end{tabular}

Note. Source: Prepared by the author.

By following these three rules, the prisoners' dilemma can be reformulated thus. Two suspects are captured and put in separate cells, and there is no possibility for them to communicate with each other. Interrogated at different times, they receive two proposals: to confess or not confess to the crime. If both confess, each of them will be punished with a five year sentence. If both do not confess, they will be set free because they are innocent till proven guilty and there is no evidence against them. If only one confesses, he is given a one-year sentence and the other is imprisoned for 10 years.

This new configuration of the game can be seen clearly in Table 3.

Table 3

Strategic Representation of Modified Prisoner's Dilemma

\begin{tabular}{|c|c|c|c|}
\hline & & \multicolumn{2}{|c|}{ Prisoner A } \\
\hline & & Guilt confessed & Guilt not confessed \\
\hline \multirow{2}{*}{ Prisoner B } & Guilt confessed & 5.5 & 1.10 \\
\hline & Guilt not confessed & 10.1 & 0.0 \\
\hline
\end{tabular}

Note. Source: Prepared by the author.

Like the original form of the game, they are naturally faced with transaction costs because they are in separate cells. Therefore, the possibility of establishing any kind of cooperation between them that will give them immediate freedom or freedom after the shortest possible time becomes as difficult as the original dilemma. For the best response function, this game has two Nash equilibriums in pure strategies. The first equilibrium is when both opt for the strategy of confessing. This combination of strategies results in five years imprisonment for both prisoners. The second equilibrium occurs when both choose not to confess, enabling them to achieve immediate freedom. Both are equally valid because once this balance has been achieved, there is no motivation to divert.

In this particular game, even if there is no voluntary cooperation because they cannot bargain due to transaction costs (a violation of the Coase theorem), the prisoners achieve an equilibrium whose result would be the same as that achieved through cooperation. And not even then do they relinquish any type of rationality.

\section{Cooperative Implementation: Final Offer Arbitration}

Many situations in which organizations are included can be extended and analyzed with the structure outlined above, such as the relationship between suppliers and buyers, the formation of joint ventures and outsourcing. To provide an example and context, here a specific situation is analyzed in the organizational environment where it can be seen that correct implementation can make a competitive dimension become a 
cooperative dimension.

Holding negotiations between employers' organizations and trade unions is notoriously difficult when it comes to labor issues, especially negotiating salaries and wages (Crawford, 1979). As is well known, companies and workers have different interests, and workers would like to see their salaries reach the highest possible level and companies wish to keep salaries as low as possible. Supposing that workers would like a raise of 110 , they ask for more, for example 140. Companies intend to pay 90 and propose 70 . As initial proposals are widely different, negotiations can reach an impasse, where an agreement (equilibrium) is not achieved because competitive strategy prevails, and besides the interest of the agents involved, there are no elements (rules and instruments) that result in cooperation. A good example of the difficulties in negotiating wages and salaries can be found in Dixit and Nalebuff (1993).

The implementation arises, in this context, with a negotiation structure (game) that allows cooperation to be achieved more easily. The rules implemented in this game include a new element, called an arbitrator (mediator), whose function is to analyze the situation impartially and make decisions concerning the negotiation (Bloom \& Cavanagh, 1987). This game structure is defined as final offer arbitration.

The final offer arbitration game involves two players and an arbitrator, and it is developed, although not necessarily, over two periods of time $\left(t_{0}, t_{1}\right)$. At $t_{0}$, the players put forward their proposals, and at $t_{1}$ the arbitrator chooses one of the proposals, the game is ended and both players are obliged to accept the decision (Yildiz, 2011). Therefore, the game is perceived to achieve an equilibrium, i.e., that the negotiation has a solution. It remains to be seen whether this equilibrium tends to be cooperative, i.e., does the result satisfy those participating in the game as fully as possible?

Supposing there are criteria that point to an appropriate value for raising salaries, and that these criteria are common knowledge, including the arbitrator. Using these criteria, both the players and the arbitrator can propose a value. The players know that the arbitrator is impartial, and therefore, will not favor any particular side. If the arbitrator considers 100 to be the suitable value (a value known only to the arbitrator) then this will be the reference point for the final decision. The winning proposal will be the one that comes closest to 100 . Therefore, if the company offers 95 and the workers want 110, the arbitrator will chose 95, because this value has the smallest difference between itself and the reference point. Therefore, it is no longer a matter of finding a common value but determining a value that is closest to the reference.

As the negotiators would like to present winning proposals, an action that reaffirms the rational character of the players and the competitive edge of the game, they will present values that tend to be closer to the reference value. When "attempting" to present a proposal that is closer to the reference value, each player relinquishes higher individual gains (bearing in mind that lower salaries constitute gains for the company), which favors the other player, since this relinquished value is a type of transfer of favor from the other player.

In a situation like this, competition does not cease to exist, but it is possible to see that the result is very close to what would have been achieved in a situation of cooperation. And the result of cooperation exists because each negotiator's proposal incorporates the interests of the other, i.e., each negotiator internalizes the interests of the other player because he indirectly recognizes his real needs. Therefore, the role of implementation is to construct rules, such as final offer arbitration, which enables participants to achieve cooperation or a similar situation. 


\section{Final Considerations}

There is a very large field still to be explored concerning whether it is possible to establish a connection between new institutional economics and the game theory, and this connection is the implementation theory. Indeed, it is assumed that institutions affect the social and economic environment, and if the implementation theory aims to construct games that achieve a desired equilibrium, their combination makes it possible to understand better social, economic, and business phenomena that remain obscure. It would also make it possible to institutionalize elements that guarantee higher levels of efficiency and performance, at both the micro- and macro- level.

Although it is already known that prisoner's dilemma is the fruit of transaction costs, this article sought to demonstrate that the presence of transaction costs partially explains this dilemma. The prisoner's dilemma is also the result of the rules set when the game was implemented, which guide the behavior of the players to strategies whose equilibrium is not cooperative.

The implementation presented in this article shows that, depending on how the game is constructed, it has considerable influence on the equilibrium that can be achieved. This can be seen in the reformulation of the rules of play in the prisoner's dilemma. In the original model, if the person is innocent or there is no evidence to convict him, he will behind bars for a shorter period of time, while if he is actually guilty and cooperates in clearing up the crime, he will be immediately set free. The change in the rule reverses these implications. If the person is innocent and there is no evidence to convict him, he will be set free, and he will only remain behind bars if he is guilty.

With this overhaul of the rules, the possibility of cooperation emerges because Nash's equilibrium is achieved from the strategies of cooperating and cooperating, in addition to the equilibrium stemming from the strategies of not cooperating and not cooperating. This theoretical result strengthens the legitimacy and the role of the rules and especially the institutions, as long as their actions (norms, laws and others) provide positive guidance for social, economic, and business conduct. At the same time, it encourages the preparation of other works that help to understand this phenomenon and its developments more fully. To illustrate this, the final offer arbitration shows that it is possible to set rules and other mechanisms that make cooperation easier to achieve.

\section{References}

Allen, D. (1999). Transaction costs. Retrieved January 20, 2011, from http://www.encyclo.findlaw.com/0740book.pdf

Andreoni, J., \& Miller, J. H. (1993). Rational cooperation in the finitely repeated prisoner's dilemma: Experimental evidence. The Economic Journal, 103, 570-585.

Aoki, M. (2001). Toward a comparative institutional analysis. MIT Press.

Axelrod, R. (1984). The evolution of cooperation. New York: Basic Books Publishers.

Axelrod, R. (1997). The complexity of cooperation. Princeton, N.J.: Princeton University Press.

Axelrod, R. (2001, July). Theoretical Foundations of Partnerships for Economic Development, prepared for World Bank Conference on Evaluation and Development-the Partnership Dimension, Washington D. C..

Bloom, D. E., \& Cavanagh, C. L. (1987). Negotiator behavior under arbitration. American Economic Review Papers and Proceedings, 77, 353-358.

Cárdenas, E., \& Ojeda, J. (2002). La Nueva Economía Institucional y la Teoría de la Implementación. Revista de Economia Institucional, 4(6), 153-169.

Coase, R. (1960). The problem of social cost. Journal of Law and Economics, 3, 1-44.

Coase, R. (1937). The nature of the firm. Economica, 4(16), 386-405. 
Crawford, V. (1979). On compulsory-arbtration schemes. Journal of Political Economy, 87, 131-159.

Demsetz, H. (1964). The exchange and enforcement of property rights. Journal of Law and Economics, 7, 11-26.

Dixit, A. K., \& Nalebuff, B. J. (1993). Thinking strategically: The competitive edge in business, politics and everyday life. New York: Norton \& Company.

Furubotn, E. R., \& Richter, R. (2005). Institutions and economic theory. The University of Michigan Press.

Greif, A. (1997). Economic history and game theory: A survey. Retrieved December 3, 2010, from http://www-siepr.stanford.edu/workp/swp97017.pdf

Heckathorn, D. D., \& Steven, M. M. (1987). Bargaining and the sources of transaction costs: The case of government regulation. Journal of Law, Economics, and Organization, 3(1), 69-98.

Hicks, J. R. (1935). A suggestion for simplifying the theory of money. Economica, 2(5), 1-19.

Hurwicz, L. (1973). The design of mechanisms for resource allocation. American Economic Review, 63, 1-30.

Klein, P. G. (1999). New institutional economics. In Encyclopedia of Law and Economics. Retrieved February 17, 2011, from http://encyclo.findlaw.com/0530book.pdf

Lee, J. E., \& Sabourian, H. (2007). Coase theorem, complexity and transaction costs. Journal of Economic Theory, 135, $214-235$.

Normann, H. T., \& Wallace, B. (2011). The impact of the termination rule on cooperation in a prisoner's dilemma experiment. $\begin{array}{lllllll}\text { Working } & \text { Paper } & \text { No. } & \text { Retrieved } & \text { July } & \text { 15, } & \text { 2011, }\end{array}$ http://www.dice.uni-duesseldorf.de/Forschung/Dokumente/019_Normann_Wallace.pdf

North, D. C. (1981). Structure and change in economic history. New York: W. W. Norton \& Co..

North, D. C. (1990). Institutions, institutional change and economic performance. Cambridge University Press.

North, D. C. (1993). An interview with Douglass C. North. The Newsletter of the Cliometric Society, 8(3), 7-12.

Osborne, M. J. (2004). An introduction to game theory. New York: Oxford University Press.

Osborne, M. J. E., \& Rubinstein, A. (1994). A course in game theory. Cambridge: The MIT Press.

Poundstone, W. (1992). Prisoner's dilemma. New York: Anchor Books.

Simon, H. A. (1955). A behavioral model of rational choice. Quarterly Journal of Economics, 69(1), 99-118.

Simon, H. A. (1991). Organizations and markets. Journal of Economic Perspectives, 5(2), 25-44.

Von Neumann, J., \& Morgenstern, O. (1944). The theory of games and economic behavior. Princeton: Princeton University Press. Williamson, O. E. (1985). The economic institutions of capitalism. New York: Free Press.

Williamson, O. E. (1998). Transaction cost economics: How it works, where it is headed. De Economist, 146, 23-58.

Yildiz, M. (2011). Nash meets Rubinstein in final-offer arbitration. Economics Letters, 110(3), 226-230. 